\title{
A Review on BRT Scoring System for Malaysia Practice
}

\author{
Hamsareka Thevadass ${ }^{1}$, Goh Boon Hoe ${ }^{1, *}$, Wong Kok Cheong ${ }^{1}$, Teo Fang Yenn ${ }^{1}$, \\ Christina Chin May May, ${ }^{1}$, Yuen Choon Wah ${ }^{2}$, Yap Eng Hwa ${ }^{3}$ \\ ${ }^{1}$ Faculty of Science and Engineering, University of Nottingham Malaysia, Jalan Broga, 43500 Semenyih, Selangor, Malaysia \\ ${ }^{2}$ Centre for Transportation Research, Universiti Malaya, 50603 Kuala Lumpur, Malaysia \\ ${ }^{3}$ School of Intelligent Manufacturing Ecosystem and School of Robotics, Xi'an Jiaotong-Liverpool University, 111 Ren'ai Road, \\ Suzhou Industrial Park, Suzhou, Jiangsu, People's Republic of China
}

Received December 3, 2020; Revised February 7, 2021; Accepted March 12, 2021

\section{Cite This Paper in the following Citation Styles}

(a): [1] Hamsareka Thevadass, Goh Boon Hoe, Wong Kok Cheong, Teo Fang Yenn, Christina Chin May May, Yuen Choon Wah, Yap Eng Hwa, "A Review on BRT Scoring System for Malaysia Practice," Civil Engineering and Architecture, Vol. 9, No. 2, pp. 410-419, 2021. DOI: 10.13189/cea.2021.090214.

(b): Hamsareka Thevadass, Goh Boon Hoe, Wong Kok Cheong, Teo Fang Yenn, Christina Chin May May, Yuen Choon Wah, Yap Eng Hwa (2021). A Review on BRT Scoring System for Malaysia Practice. Civil Engineering and Architecture, 9(2), 410-419. DOI: 10.13189/cea.2021.090214.

Copyright $\bigcirc 2021$ by authors, all rights reserved. Authors agree that this article remains permanently open access under the terms of the Creative Commons Attribution License 4.0 International License

\begin{abstract}
Bus Rapid Transit (BRT) is the bus-based public transit system, which is designed to maximize the efficiency, capacity and reliability comparatively to the existing traditional bus system. Generally, this advantageous, cost-effective and convenient BRT comprises the designated laneways, priority-given intersections, off-board fare collection and more, which reduces the delay in travelling and increasing the capacity as well. In order to maintain the standard of the BRT, where to be distinguished from the conventional bus system, there are few BRT scoring systems available from the Institute for Transportation and Development Policy (ITDP) and Federal Transit Association (FTA). However, each scoring system has its pros and cons, which might not be suitable for the Malaysian practice. In addition, the scoring system is not very emphasizing on the BRT stations in regards with the locations, supporting infrastructures and more, which has the potential to affect the transit ridership. This paper reviews the existing BRT standards that have been utilized in assessing the existing BRTs all around the world. Moreover, this reviewing reflects the compliances or suitability of the available BRT standards to be used in assessing Malaysia BRTs. This method of reviewing provides more focused scoring guidelines which can complement the Malaysian practice in a more contextual manner. The identified gap in the existing BRT standards will be recommended with newly formulated guidelines that fit more into Malaysia context and encourage more inclusivity which promotes active transportation. Hence, the newly formulated BRT standard
\end{abstract}

as per Malaysia context can enhance the existing design principles which can promote more ridership.

Keywords Bus Rapid Transit, BRT Scoring System, Malaysia, ITDP

\section{Introduction}

Bus Rapid Transit (BRT) is a modern urban public transportation with a constantly increasing worldwide significance due to its flexibility in implementing or constructing on designated area and its lower to medium fare costings. The consumer centric transit, BRT has continued to adapt and adopt new technological advancement, strengthening its position in the mass transit market. Comparatively, BRT is the new approach of mass transits, where it has the potential to provide high-quality transport system and the capacity to accelerate developments near the BRT stations. Moreover, Canadian Urban Transit Association addressed BRT in fuller and cohesive concept "as a rubber-tired rapid transit service that combines stations, vehicle, running ways and a flexible operating plan into a high-quantity, customer-focused service that is fast, reliable, comfortable and cost-efficient" [1]. In BRT, busses are used as the main mode is transportation and the network is often built to offer the same level of service as to the rail systems in the world, but additionally providing an amount of 
advantage that can hardly be achieved by the rail systems [2].

The advantages in BRT as compared to the rail system are viewed in several variables such as implementation or constructions costs. For instance, the capital needed for rail systems is relatively higher than the BRTs lane, this is simply because rail systems need specific permanent tracks for operations meanwhile, dedicated bus lanes for BRTs can be designated on any suitable roadway or traffic, and expandable. In usual terms, BRT's distinguishing characteristic is the dedicated bus lanes, which can be designated on regular roads and further re-designated into grade-separated roads with limited access and then into bus-only lanes [2]. The easy construction and continued implementation highlight BRT as one of the major options for mass transits in many countries.

In order to ensure an international class of service for all the BRT passengers in the world, and to maintain a consistent feature in the BRT stations and corridor, various documents were created, one of these is the Institute for Transportation and Development Policy BRT Standard, which is used to determine a consensus definition for the BRTs; it also identifies the best practices. This rating tool has several elements that make BRT to be distinguished from the regular conventional buses. The main categories enlisted in the BRT Standard are BRT Basics, Service Planning, Infrastructure, Stations,
Communications, Access and Integration and finally Point Deduction Category. Each of these categories has its sub-elements that have specific scores dedicated for each of them [3]. Generally, the BRT Standard focused more on the designing factors, rather than activities or several other factors that can actually be used together with the other categories to evaluate each BRT in the world or even to design the future BRT lines.

Hence, this paper reviews the BRT Standard and BRTs all around the world. To the best of knowledge, in the BRT Standard by ITPD [3] the categories enlisted in the Standard can be further detailed in a more holistic way which can also cover the built environment part, which has the potential to increase the ridership and comfort of the passengers. Also, the review made in Bus Rapid Transit [4] regarding the BRT was descriptive. Hence, this paper will recommend other alternatives for comparison for BRTs, which is more quantifiable.

\section{The BRT Scoring System}

Generally, BRT in all over the world is scored using the ITDP's BRT Standard, but in United States Federal Transit Administration (FTA)'s BRT Standard is being utilized for the scoring. This is the customization of the standard according to its national standard and situation.

Table 1. The Bus Rapid Transit Standard, ITPD

\begin{tabular}{|c|c|c|c|}
\hline & Category & Elements & Explanation \\
\hline 1 & BRT Basics & $\begin{array}{l}\text { Dedicated Right-of-Way } \\
\text { Busway Alignment } \\
\text { Off-Board } \\
\text { Fare Collection } \\
\text { Intersection Treatments } \\
\text { Platform-level Boarding } \\
\end{array}$ & $\begin{array}{l}\text { The five elements significantly contribute to reducing } \\
\text { causes of congestion delay, disputes with other cars, } \\
\text { and alighting and boarding of passengers, thereby } \\
\text { improving efficiency and reducing operating expenses }\end{array}$ \\
\hline 2 & Service Planning & $\begin{array}{c}\text { Multiple Routes } \\
\text { Express, Limited, and Local Services } \\
\text { Control Center } \\
\text { Located in Top Ten Corridors } \\
\text { Demand Profile } \\
\text { Hours of Operations } \\
\text { Multi-Corridor Network }\end{array}$ & $\begin{array}{l}\text { The elements contribute to the proper location } \\
\text { selection process which will impact the ridership as } \\
\text { well as the accommodations of multiple types of buses } \\
\text { to cover the first-last mile destinations }\end{array}$ \\
\hline 3 & Infrastructure & $\begin{array}{c}\text { Passing Lanes at Stations } \\
\text { Minimizing Bus Emissions } \\
\text { Stations Set Back from Intersections } \\
\text { Center Stations } \\
\text { Pavement Quality }\end{array}$ & $\begin{array}{l}\text { These elements highly affect the quality of the BRT } \\
\text { service in regards to buses, stations and the } \\
\text { environment as well. Moreover, these are important } \\
\text { elements to take in when planning and constructing the } \\
\text { corridors and lines }\end{array}$ \\
\hline 4 & Stations & $\begin{array}{l}\text { Distances Between Stations } \\
\text { Safe and Comfortable Stations } \\
\text { Number of Doors on Bus } \\
\text { Docking Bays and Sub-stops } \\
\text { Sliding Doors in BRT Stations } \\
\end{array}$ & $\begin{array}{l}\text { The built-up area of the stations or distance between } \\
\text { the stations, wide, attractive and weather-protections } \\
\text { of a station is evaluated to enhance the comfort of the } \\
\text { passenger and the service of the BRT. }\end{array}$ \\
\hline 5 & Communication & $\begin{array}{c}\text { Branding } \\
\text { Passenger Information }\end{array}$ & $\begin{array}{l}\text { These elements about having unique brand or identity } \\
\text { and providing a real-time passenger information are } \\
\text { considered critical to a positive overall experience. }\end{array}$ \\
\hline 6 & Access \& Integration & $\begin{array}{c}\text { Universal Access } \\
\text { Integration with Other Public Transport } \\
\text { Pedestrian Access } \\
\text { Secure Bicycle Parking } \\
\text { Bicycle Lanes } \\
\text { Bicycle-sharing Integration }\end{array}$ & $\begin{array}{l}\text { These elements contribute to making the station more } \\
\text { accessible by all, integrating with multiple mode of } \\
\text { transportation, connecting active transport users. }\end{array}$ \\
\hline
\end{tabular}




\subsection{The ITDP BRT Standard}

The ITDP BRT Standard is a masterpiece of the international leaders in bus transportation designed to create a shared concept of BRT and ensuring that the BRT system offers more reliably international passenger experiences, substantial economic returns and significant environmental impact. The experts contribute to the consistent stream of sound expert advice on BRT and are the foundation for maintaining the BRT standard's legitimacy. Almost all the BRT projects in the world are evaluated by the scoring system and the coherence of the BRT to the standard objectives are ensured. The design-based BRT Standard focuses on various categories that help the countries to understand the basic designing needs of the BRT and some other categories that can distinguish the BRTs from other normal operational bus services. Categories and the elements are used to plan or to evaluate existing corridor specifically on the physical elements or infrastructure that can enhance the service of the BRTs. The BRT Standard has 6 categories with elements respectively as shown in the Table 1, which explains the scope of the categories.

Points awarded for corridor design features which enhance operational efficiency and service quality most significantly. The points will serve as indicators for an excellent customer service and best framework planning and design practices. In addition, the indicators and weights should be available conveniently and equitably and robust to a wide range of BRT corridors such as lower ridership, larger-volume corridors and many more.

The highest number of points that a system would gain would be 100. Rankings in gold, silver and bronze all represent well-designed corridors which have established perfection. The Gold Standard BRT (85 points and above) offers the maximum level of organizational performance and efficiency while providing good service quality. It is possible on every suitable corridor that has sufficient demand to support improvements in BRT and these projects have the ability to lead both the public as well as other cities. The Silver Standard BRT (70-84 points and above) encompasses most aspects of international successful practices and is expected to be cost-effective in any corridor with ample market to support investment in BRT. Such systems achieve a higher efficiency in operation and level of service.

Last but not least, the Bronze Standard BRT (55-69 points) fulfils BRT's concept firmly and is aligned with international good practice. The standard BRTs have certain features which lift it above the basic BRTs and achieve better operational or system quality than the basic BRT. Basic BRT relates to a basic set of aspects considered by the Technical Committee to be essential to $\mathrm{BRT}$ in general and it acts as the precondition to any BRT corridor retrieving a Gold, Silver or Bronze standard ranking [3].

The BRT Standard is based on measurable design features correlated with high efficiency, rather than significant contribution to an existing. One of the purposes for this approach is that the BRT Standard has the ability to evaluate both the planned and constructed corridors. It guides in designing the corridor prior to the construction. This standard is operational for both the planned and built BRT corridors. This BRT Standard is considered as a balance sheet to the cost-effectiveness measurements and system-performance evaluations which include the Performance Standard which comprises a specific set of directed criteria designated to capture the critical elements of productivity in service, productivity, efficiency and speed [5].

However, some institutions have adopted and customized the ITDP BRT Standard by adding certain guidelines that fit into the local context and beyond. Certain categories in the BRT Standard were also combined with the other category to have extra guidelines that are emphasized in the evaluation process.

\subsection{Federal Transit Administration (FTA) BRT Standard}

The Federal Transit Administration (FTA) in Malaysia assists local public transportation systems financially and technically including busses, metro, commuter trains, light rail and ferries. FTA also manages safety precautions and helps in developing research into next-generation technology. Moreover, one of the goals of the FTA is to contribute local and state policymakers with the resources needed in order to make informed investment decisions about transportation. Coherently with this aim in mind, the report entitled Characteristics of Bus Rapid Transit for Decision-Making (CBRT) was prepared by the FTA. This report provides the transportation related professionals and decision makers with all sorts of knowledge and data needed to uphold and support the development, evaluation and implementation of bus rapid transit concepts. This report defines the future, physical, administrative, operational cost, efficiency and potential advantages of BRTs categories and elements both discretely and combined as integrated systems. The report's targeted congregations comprise the urban transportation related professionals and stakeholders involved in constructing and evaluating the high-performance transits where BRT is one of the preferences.

According to the CBRT [6], "Dedicated transitways/ busways, limited-stop and express services and exclusive bus lanes have become part of the transit planning vocabulary because they have enhanced speed and reliability and thus encouraged transit usage; however, there is uncertainty among elected officials and even some transit professionals about what BRT is and how it differs from conventional bus services and systems. It is noted in this report that there is uncertainty in the existing BRT evaluations, which has been in use for decades; claiming that some officials or even urban transportation 
professional's vagueness in distinguishing the BRTs from the conventional bus service systems. Options or elements available for BRT evaluation are broad and comprehensive that there is an array of varied elements to be integrated into the BRT systems. The BRT systems cannot look the same within a given region letting alone between any different urban areas.

FTA highlights the six major BRT Elements, such as the Running Ways, Stations, Vehicles, Fare Collections, Intelligent Transportation System (ITS) and Service and Operations Plan. These elements are integrated with the designing or fashion issues such as the Branding and Seamless Interface Requirements which would maximize the impact of the investments. For instance, when implemented in combined with other elements, the efficiency of certain elements is either amplified or negated (see Table 2).

Table 2. The BRT Elements \& Primary Consideration for Integration

\begin{tabular}{cl}
\hline BRT Elements & \multicolumn{1}{c}{ Explanation } \\
\hline Running Ways & Branding \\
Stations & -Developing a strategy to foster the BRT brand \\
Vehicles & -Communicating visually via logos, color \\
Fare Collections & themes, graphics \\
\cline { 2 - 2 } Intelligent & Seamless Interface Requirements \\
Transportation & -BRT Elements shall function seamlessly with \\
System (ITS) & other elements \\
Service \& & -Involving combinations of elements along \\
Operations Plan & with design issues \\
\hline
\end{tabular}

Source: ITDP BRT Standard, 2016

Table 3. Primary Consideration for Integration \& The Effect of BRT Elements

\begin{tabular}{|c|c|c|c|}
\hline & $\begin{array}{c}\text { Performance } \\
\text { Attribute }\end{array}$ & Performance Measure & Effect of BRT Elements on Performance Attributes \\
\hline \multirow{3}{*}{1} & \multirow{3}{*}{ Travel Time } & $\begin{array}{l}\text { 1. Running Time } \\
\text { Time spent in vehicle }\end{array}$ & $\begin{array}{l}\text { 1. Running Way - Running Way \& Segregation } \\
\text { 2. Stations - Passing Capability } \\
\text { 3. ITS - Transit Vehicle Prioritization \& Driver Assist and Automation } \\
\text { 4. Service and Operations Plan - Station Spacing \& Schedule Control Method }\end{array}$ \\
\hline & & $\begin{array}{l}\text { 2. Dwell Time } \\
\text { Time spent in the vehicle } \\
\text { stopped at station }\end{array}$ & $\begin{array}{l}\text { 1. Stations - Platform Height \& Platform Layout } \\
\text { 2. Vehicles - Vehicles Configurations \& Passenger Circulation Enhancement } \\
\text { 3. Fare Collection - Fare Collection Process \& Fare Transaction Media } \\
\text { 4. ITS - Driver Assist and Automation } \\
\text { 5. Service and Operations Plan - Service Frequency \& Schedule Control } \\
\text { Method }\end{array}$ \\
\hline & & $\begin{array}{l}\text { 3. Wait Time } \\
\text { Waiting time to board to } \\
\text { transit service } \\
\text { 4. Transfer time } \\
\text { Transferring time } \\
\text { between BRT transit to } \\
\text { other types of transit }\end{array}$ & $\begin{array}{l}\text { 1. Stations - Station Type } \\
\text { 2. ITS - Operation Management \& Passenger Information } \\
\text { 3. Service and Operations Plan - Service Frequency, Route Structure \& } \\
\text { Schedule Control Method }\end{array}$ \\
\hline 2 & Reliability & $\begin{array}{l}\text { Service Reliability } \\
\text { - Multiple service options } \\
\text { - Quick responds to } \\
\text { delays / disruptions } \\
\text { - Availability of } \\
\text { "contingency" resources }\end{array}$ & $\begin{array}{l}\text { 1. Stations - Passing Capability \& Platform Layout } \\
\text { 2. ITS - Vehicle Prioritization Systems, Operations Managements \& Passenger } \\
\text { Information System } \\
\text { 3. Service and Operations Plan - Service Frequency \& Span }\end{array}$ \\
\hline \multirow[t]{2}{*}{3} & \multirow[t]{2}{*}{ Image \& Identity } & $\begin{array}{l}\text { 1. Identity } \\
\text { - Customer Perception of } \\
\text { Attractiveness } \\
\text { - General Customer } \\
\text { Satisfaction }\end{array}$ & $\begin{array}{l}\text { 1. Running Way - Running Way Segregation, Differentiation \& Station Type } \\
\text { 2. Vehicles - Vehicles Configurations, Aesthetic Enhancement \& Propulsions } \\
\text { 3. Fare Collection - Fare Collection Process \& Fare Transaction Media } \\
\text { 4. ITS - Vehicle Priority, Driver Assist and Automation \& Passenger Information }\end{array}$ \\
\hline & & $\begin{array}{l}\text { 2. Contextual Design } \\
\text { - "quality" design that } \\
\text { integrates with the urban } \\
\text { communities }\end{array}$ & $\begin{array}{l}\text { 1. Running Way - Running Way Segregation } \\
\text { 2. Station - Basic Type Station } \\
\text { 3. Vehicle - Aesthetic Enhancement }\end{array}$ \\
\hline \multirow{2}{*}{4} & \multirow{2}{*}{$\begin{array}{l}\text { Passenger Safety } \\
\text { and Security }\end{array}$} & $\begin{array}{l}\text { 1. Identity } \\
\text { - Customer Perception of } \\
\text { Attractiveness } \\
\text { - General Customer } \\
\text { Satisfaction }\end{array}$ & $\begin{array}{l}\text { 1. Running Way - Running Way Segregation \& Guidance } \\
\text { 2. Stations - Platform Height } \\
\text { 3. Vehicles - Vehicles Configurations } \\
\text { 4. ITS - Driver Assist \& Automation Technology }\end{array}$ \\
\hline & & $\begin{array}{l}\text { 2. Security } \\
\text { Crime rates on transit } \\
\text { system per unit of output } \\
\text { (service hours / service } \\
\text { miles) }\end{array}$ & $\begin{array}{l}\text { 1. Stations - Station Design } \\
\text { 2. Vehicles - Aesthetic Enhancement } \\
\text { 3. Fare Collection - Fare Collection Process \& Fare Media } \\
\text { 4. ITS - Operations Management, Safety and Security Technologies }\end{array}$ \\
\hline 5 & System Capacity & $\begin{array}{l}\text { 1. BRT Vehicle } \\
\text { (Passenger) Capacity } \\
\text { 2. BRT Station (Vehicle } \\
\text { and Passenger) Capacity } \\
\text { 3. BRT Running Way } \\
\text { (vehicle) Capacity }\end{array}$ & $\begin{array}{l}\text { 1. Running Way - Running Way Segregation } \\
\text { 2. Stations - Station Type, Platform Heights, Platform Layout \& Passing } \\
\text { Capability } \\
\text { 3. Vehicles - Vehicle Configurations } \\
\text { 4. ITS - Vehicle Prioritization, Driver Assist and Automation \& Operations } \\
\text { Management Systems } \\
\text { 5. Service \& Operations Plan - Service Frequency \& Operating Procedures }\end{array}$ \\
\hline
\end{tabular}

Source: ITDP BRT Standard, 2016 
Accordingly, information on performance measures and outcomes such as the capacity of the ridership, operational and maintenance expenses and ridership will be comprised as discrete element levels. The FTA discusses five key BRT system performance aspects, including Travel Time, Reliability, Image \& Identity, Passenger Safety \& Security and System Capacity (see Table 3).

Each performance measure is affected by the BRT Elements enlisted accordingly; any nullifying BRT Element can result accordingly in the performance measure. The Performance Measure acts as the evaluation indicators under the Performance Attributes. This FTA report is widely utilized by many researchers to review the BRTs in the world. This customized performance evaluation covers a wider array of characteristics of BRT.

\section{Reflection \& Recommendation}

The reviewing of the BRT scoring systems reflects that there is a need for a more focused scoring guidelines that can complement Malaysian practice as well as a strong emphasize on the location of the BRT stations and the infrastructures. These extra focus on the guidelines can increase the ridership and create a quality corridor. The recommendations cover 3 main areas, knowingly the Demand Profiling, Universal Access and Amenities, which can elevate the design principles and at the same time enhance the evaluation process.

\subsection{Demand Profiling}

According to the ITDP Scoring Standard, the Demand Profile Guidelines for instance, is given that the BRT corridor must encompass the highest demand road segment within 2-kilometre distance from either end of the corridor. Highest quality of the busway alignment is emphasized in this profile section. Adding on to that, concluding the demand segments via Trunk Corridor Tiers given cannot be used in all context. Moreover, there are more physical elements that can actually reflect the demand for the transits (see Table 4).

Table 4. Scoring Guideline for Demand Profile (Category: Service Planning)

\begin{tabular}{lc}
\hline \multicolumn{1}{c}{ Demand Profile } & Points \\
\hline $\begin{array}{l}\text { Corridor includes highest demand segment, which has a } \\
\text { Tier 1 Trunk Corridor configuration }\end{array}$ & 3 \\
\hline $\begin{array}{l}\text { Corridor includes highest demand segment, which has a } \\
\text { Tier 2 Trunk Corridor configuration }\end{array}$ & 2 \\
\hline $\begin{array}{l}\text { Corridor includes highest demand segment, which has a } \\
\text { Tier 3 Trunk Corridor configuration }\end{array}$ & 1 \\
\hline Corridor does not include highest demand segment & 0 \\
\hline
\end{tabular}

Source: ITDP BRT Standard, 2016

At some cases, it is beyond what physical infrastructure holds for the demand profiling. For instance, a research by Bento et al., [7] investigated the correlation between the potential demand for public transportation to the spatial structural elements of the areas inclusive of the adjacent land-use, population distribution, socioeconomic characteristics and etc. When it comes to land-use, urban form is a vital element that influences the demand for travel. Urban economics estimates the structure or the form of the area that will influence the mode of transportation or the number of distances travelled by every household.

A relative by the Mineta Transportation Institute investigates the vehicles dependency in about 46 international urban areas, whereas 13 of those areas are in the United States, concluded the vehicle dependency to be most critical in the US, related more in the low-density areas or in auto-focused land use patterns. Moreover, two more studies by Kuby [10] and Arnab Chakraborty [11] have found positive correlation between the ridership, urban form, and transit demand. Research by Chakraborty and Mishra is correlated the connections between the transit ridership, land-use and the socio-economic as determents for transit demands. Therefore, a significant need in demand profiling is vital, as the guidelines that be further expanded in order to make sure that the true demand is captured using the land-use activities' and urban form impact as well (see Table 5). A radius of 500 meters to 1 kilometer was set coherently to the maximum walkable distance and walkability catchment areas coverage.

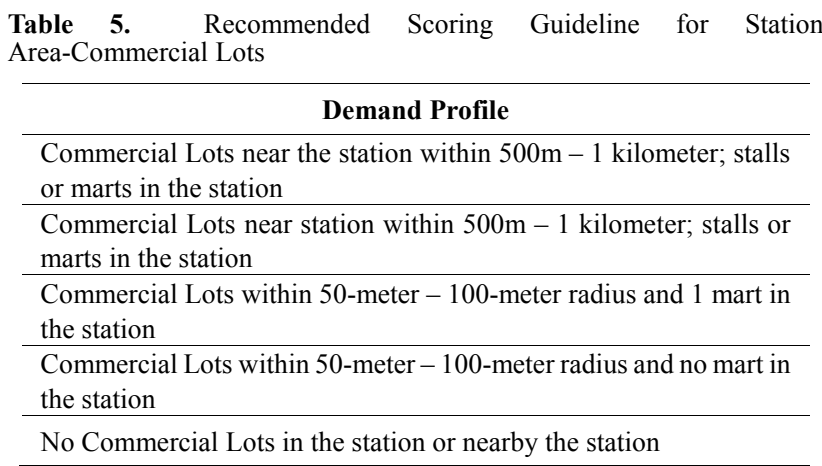

Source: Author, 2020

The interaction between the transit stations and surrounding urban form or land use, affects the ridership and the travel demand as well. According to the research by Berawi [13], explaining the importance of diversifying the land use optimization to increase the growth in ridership. In this recommendation, the focused on commercial lots as in shopping malls, commercial shop-lots, stalls etc. are because most of the commercial mix areas can create a purpose for the passengers to commute forth and back. To add on, Malaysians are often attracted to stalls along the streets, thus by having these types of commercial activities near the stations can encourage more people to commute via BRT. Moreover, in some areas, commercial mix areas consist of various land-uses that can to encourage ridership. Hence, a 
demand profiling or capturing can be evaluated using a specific guideline that is customized according to the Malaysian context.

\subsection{Universal Access}

Another important category in the ITDP Scoring Standard is the Access and Integration, which indicates the accessibility of the station for all and the integration of the stations with other modes of transportations. One of the most important elements under this category is the Universal Access, the huge emphasis on this element is vital because according to a report from the World Bank Group, by the year 2050, the world's population in urban itself will escalade by 2.5 billion people achieving $66 \%$ of the globe's total population. Henceforth, the amount of ridership in urban areas is expected to anticipate $50 \%$ growth from 2005 to 2025. Accommodating enough universal access facilities or infrastructure is important in every BRT station which can cater the future need (see Table 4).

According to the ITDP Scoring Standard, the BRT system should be universally designed where people with disabilities, including physically, visually, hearing impaired as well as people with temporary disabilities, children, elderly, parents with baby-strollers should commute without any hindrance. The scoring guideline emphasizes the need for accessible space for wheelchairs, drop curbs, Braille readers and tactile blocks (guiding blocks for visually impaired people) to be installed in every station. Yet, the scoring table does not reflect all these important universal accessibilities, which is necessary to be put in detail for developers to understand the importance of universal access in every station (see Table 6).

Table 6. Scoring Guideline for Universal Access (Category: Access \& Integration)

\begin{tabular}{lc}
\hline \multicolumn{1}{c}{ Universal Access } & Points \\
\hline Full accessibility at all stations and on all vehicles & 3 \\
\hline Partial accessibility at all stations and on all vehicles & 2 \\
\hline $\begin{array}{l}\text { Full and partial accessibility at some stations and on } \\
\text { some vehicles }\end{array}$ & 1 \\
\hline Corridor not universally accessible & 0 \\
\hline
\end{tabular}

Source: ITDP BRT Standard, 2016

This is vital for every passenger especially for those with disabilities or even temporary disabilities to ensure that they do not encounter any unexpected obstacles. That would lead to a broken trip which will eventually decrease the ridership of the BRT. This inaccessible situation has a detrimental impact on People with Disabilities' (PWD) involvement in the social and economic system. Hence, complementing every station with proper and well-maintained transportation facilities that are safe, comfortable and convenient will encourage full involvement in the public transportation such as BRT.

As been reviewed, Universal Access is a very significant element that plays a huge role in catering the current ridership demand and the future demand as well, which was forecasted to urban population will increase by $66 \%$ by 2050 [14]. It is fundamental to remove the barriers and accommodate fundamental access to disabled people to accomplish equity in terms of universal accessibility. For this part, three recommendation elements were proposed regarding the Universal Access such as Guiding Block, Inclusive Signage and Installation of Curb Ramps (see Table 7).

Table 7. Recommended Scoring Guideline for Universal Access: Guiding Block

\begin{tabular}{l}
\hline Guiding Block (for visually impaired people) \\
\hline Installed in suitable points and well connected, contrast in color and \\
detectable; well maintained \\
\hline Installed at some important points and well connected or detectable; \\
well maintained \\
\hline Installed at some important points but poorly connected or not \\
detectable; not maintained \\
\hline Installed at departing / boarding only and detectable; maintained \\
\hline Installed at departing / boarding only and not detectable; not \\
maintained \\
\hline No guiding blocks installed \\
Source: Author, 2020
\end{tabular}

Guiding block is installed to specifically guide visually impaired people to navigate through places. It connects important nodes such as the boarding area, junctions where the turning points are located, upon crossing areas and etcetera. Hence the installation of the guiding block can help them to commute independently. At the same time, these installations have to be done in abovementioned locations; ensuring the continuity to important nodes as well.

Next, Table 8 are fundamental for all people including disables, elderly people, and even children. Inclusivity in right-of-way is highly recommended to encourage all groups of people to commute as well. This directly will elevate the ridership in BRT.

Table 8. Recommended Scoring Guideline for Universal Access: Inclusive Signages

\begin{tabular}{l}
\hline Inclusive Signages \\
\hline Installed in suitable points and well connected, contrast in color and \\
detectable; well maintained \\
\hline Installed at some important points and well connected or detectable; \\
well maintained \\
\hline Installed at some important points but poorly connected or not \\
detectable; not maintained \\
\hline Installed at departing / boarding only and detectable; maintained \\
\hline Installed at departing / boarding only and not detectable; not \\
maintained \\
\hline No Inclusive signages installed \\
\hline
\end{tabular}

Source: Author, 2020

The following recommendation is for the curb ramps which is utilized by the people with wheelchair, baby 
strollers and people bringing disables. There is no specific guideline that recommends specific number of curb ramps needed for each BRT station. Hence, this study uses the number of gates (can be egress or ingress) or staircases in the BRT station as the benchmark in order to determine the number of curb ramp needed for every BRT station. Assuming, that when the number of curb ramps is equivalent to the number of gates or staircases, it is considered $100 \%$ accommodated. Similarly followed by the $50 \%$ and more (see Table 9 ).

Table 9. Recommended Scoring Guideline for Universal Access: Number of Curb Ramps

\begin{tabular}{l}
\hline Number of Curb Ramps \\
\hline $100 \%$ Curb Ramps provided; Number of gates/ staircases = Number \\
of Curb Ramps \\
\hline $50 \%$ Curb Ramps provided; Number of gates/ staircases $\neq$ Number \\
of Curb Ramps \\
\hline $25 \%$ Curb Ramps provided; Number of gates/ staircases $\neq$ Number \\
of Curb Ramps \\
No Curb Ramps provided
\end{tabular}

Source: Author, 2020

Adding on to that, in most of the BRT stations, the curb ramps are installed; hence in order to make sure the coherence of the ramp construction on par to the minimum requirement, the ramp width, slope and effectiveness shall be emphasized in the guidelines [15]. The effectiveness in the guideline indicates the non-slip surfaces on the ramps and with handrails to ensure the ramp is safe and secure. Together with that, the minimum possible slope with 1:12 (rise: length) has been referred for better and safer utilization of the ramps (see Table 10).

Table 10. Recommended Scoring Guideline for Universal Access: Condition of the Curb Ramps

\begin{tabular}{l}
\hline Condition of the Curb Ramps \\
\hline $\begin{array}{l}\text { Curb Ramps with } 1.2 \text { meters width; 1:12 (8.33\%) slope; most } \\
\text { effective and secure }\end{array}$ \\
\hline $\begin{array}{l}\text { Curb Ramps with } 1.2 \text { meters width; 1:12 (8.33\%) slope; less } \\
\text { effective and secure }\end{array}$ \\
\hline $\begin{array}{l}\text { Curb Ramps }<1.2 \text { meters width; 1:12 (8.33\%) slope; more effective } \\
\text { and secure }\end{array}$ \\
\hline $\begin{array}{l}\text { Curb Ramps }<1.2 \text { meters width; 1:12 (8.33\%) slope; less effective } \\
\text { and secure }\end{array}$ \\
\hline No ramps; elevators and staircases only \\
\hline No ramps or curbs; only staircases \\
\hline
\end{tabular}

Source: Author, 2020

\subsection{Amenities}

Amenities are the physical infrastructure that creates comfortability to the passengers. Emphasizing of amenities in the BRT stations is very fundamental because stations are the place where every passenger spends time while waiting for their bus or even to take a transit bus. The waiting period is important, and it has to be safe and comfortable. Moreover, the accessibility to other places from the station is also aided by the presence of proper amenities. A successful amenity supply to the BRT station has the credibility to increase growth in ridership.

In this section, Category: Station is reviewed. According to the Standard, the Category: Station covers several elements in the stations from the distancing of stations, docking bays, the number of doors needed and the comfort and safety in the stations. These are generally important for a station since it is the place where passengers gather and wait to commute (see Table 11).

Table 11. Scoring Guideline for Safe and Comfortable Stations (Category: Stations)

\begin{tabular}{l}
\hline Safe and Comfortable Stations \\
\hline All stations on corridor are wide, attractive, weather-protected \\
\hline Most stations on corridor are wide, attractive, weather-protected \\
\hline Some stations on corridor are wide, attractive, weather-protected \\
\hline No stations on corridor are wide, attractive, weather-protected \\
\hline
\end{tabular}

Source: ITDP BRT Standard, 2016

In the guidelines, BRT stations are considered as the most distinguishing feature that differentiates it from regular bus service. It is emphasized that the stations should have; a platform or internal width about 3-meters (10 ft.), protected from wind, snow, heat and/or cold, etc. As well as adequate lighting, and transparent stations are highly recommended station designs. In terms of security and safety, both active and passive surveillances are encouraged such as security guards or cameras. The ridership is expected to be maintained with the station that has all these standards.

Apart from the abovementioned guidelines on the safety and comfort of the stations, in order to increase the ridership, there are many amenities that have to be injected into the station, which can create the safety and comfort, together achieving the goal of increasing the ridership. Amenities have an array of impact on the passenger behaviors and perceptions regarding the BRT service, consequently having an impact directly or indirectly on the ridership as well. For instance, from 1991 and 1993 in Miami, the Metro-Dade Transit Agency has experienced a $9.6 \%$ ridership growth mainly caused by elevating the "customer service orientation" which includes the walkways, shelters, furniture, safer access etc. Amenities are one method to promote ridership frequency and the Transit Design Game survey by the Transit Cooperative Research Program (TCRP) and results show that amenities help encourage ridership [17]. Along with the fare reduction as the mostly voted criteria to increase the ridership, a major percentage of passengers mentioned that if the intended amenities are well installed, many would consider commuting via transits.

As one of the internal factors, amenities together with an efficient service quality such as signage, furniture, public toilets, development of park-and-ride facilities, and cleanliness of the stations will contribute to ridership increase. Even though external factors such as fluctuating 
urban form, population density and policies affect the ridership, internal factors such as amenities and marketing have their significance contribution to ridership growth.

Amenities create comfort to the passengers as well as improve the security in the stations. Security in the stations can be installed like the CCTVs or by hiring security guards. Yet, covering the entire station is either expensive or might be complicated. As United States' transit systems have insufficient resources to spend on security systems or security guards. Hence, the application of Crime Prevention Through Environmental Design has been considered in the planning phase to optimize the investment for security systems or guards. This can be integrated with the positioning of the amenities, lighting, landscaping, cleanliness etc. As in for station's safety and comfortability, many criteria are to be accounted in order to evaluate any transit station, this coherently relates to the BRT stations as well.

This study highlights and recommends several amenities such as Public Toilets, Directional Signages and Safety in Stations that is considered fundamental to the BRT stations (see Table 12).

Table 12. Recommended Scoring Guideline for Amenities: Number of Public Toilets

\begin{tabular}{l}
\hline Number of Public Toilet \\
\hline $100 \%$ Public Toilets provided; Number of gates $=$ Number of toilets \\
(1 Male, 1 Female \& 1 People with Disability) \\
\hline $50 \%$ Public Toilets provided; Number of gates $\neq$ Number of toilets \\
(1 Male, 1 Female \& 1 People with Disability) \\
\hline $25 \%$ Public Toilets provided; Number of gates $\neq$ Number of toilets \\
(1 Male, 1 Female \& 1 People with Disability) \\
No public toilet provided \\
Source: Author, 2020
\end{tabular}

Similar to the Curb Ramps, there were no specific number of public toilets were fixed for a BRT station; hence, the number of gates were set as a parameter here as well in order to determine the number of public toilets needed for the stations. This is because, the number of riders fluctuates for every station or corridor, so determining the number of public toilets with the rider's data will cause inaccuracy. Hence, when the number of gates is equivalent to the number of toilets that comprises both genders and people with disabilities, it is considered $100 \%$ accommodated. Adding to that, the presence of public toilet itself is not sufficient, thus a proper maintenance is vital to keep the stations comfortable. Hence, the condition of the public toilet should be evaluated as well (see Table 13).
Table 13. Recommended Scoring Guideline for Amenities: Condition of the Public Toilets

\begin{tabular}{l}
\hline Condition of the Public Toilet \\
\hline Public toilet in the station is clean and hygienic; very effective \\
\hline $\begin{array}{l}\text { Public toilet in the station lacks of maintenance in terms of } \\
\text { cleanliness; very effective }\end{array}$ \\
\hline Public toilet in the station is clean and hygienic; less effective \\
\hline $\begin{array}{l}\text { Public toilet in the station lacks of maintenance in terms of } \\
\text { cleanliness; less effective }\end{array}$ \\
\hline $\begin{array}{l}\text { Public toilet to be accessed in the nearby malls, hospitals, } \\
\text { institutions }\end{array}$ \\
\hline No public toilet provided
\end{tabular}

Source: Author, 2020

In the condition's guidelines, the cleanliness is evaluated together with the effectiveness of the toilet conditions. The "less effective" conditions are such as slippery floors, no signage, poor lighting and ventilation, lack of maintenance or cleaners. For the "effective" conditions are toilets with clear signage, ventilation, lighting and odorless. These can be helpful to enhance the comfort level of the BRT stations. Next is the Directional signs used for right-of-way and that indicates the change of directions. The stations should be occupied with adequate signage that can help the passengers to ride seamlessly. The continuity is ensured via this signage (see Table 14).

Table 14. Recommended Scoring Guideline for Amenities: Directional Signages

\begin{tabular}{l}
\hline Directional Signs \\
\hline More than 3 directional signages at every 20 -meters not closer than \\
$6 \mathrm{~m}$; well positioned \\
\hline More than 3 directional signages at every 20 -meters not closer than \\
$6 \mathrm{~m}$; not well positioned \\
\hline Minimum 3 directional signages further away from 50 -meters from \\
each other; well positioned \\
\hline Minimum 3 directional signages further away from 50 -meters from \\
each other; not well positioned \\
\hline$<3$ directional signages; further away than 100 -meters from each \\
other; well positioned \\
\hline$<3$ signages; further away than 100 -meters from each other; not \\
well positioned \\
\hline No directional signages
\end{tabular}

Source: Author, 2020

Based on Table 14, a minimum 3 directional signages were set for one direction. Together with that, the well-positioning in the guidelines reflects the positioning of the signages at turning points. At this point change of directions occurs, where important nodes are displayed at proper locations with high visibility or traffic. This can help passengers to access places securely and comfortably. 
Adding to that point, safety in the BRT stations is very significant as well, with increase of security level in the stations it creates confidence among the passengers to commute via BRT, indirectly will induce the growth in ridership. Here, the safety is ensured via CCTV or security guards. This is the traditional way of maintaining the security in most of the transit stations (see Table 15).

Table 15. Recommended Scoring Guideline for Amenities: Safety in Stations

\begin{tabular}{l}
\hline Safety in Stations \\
\hline $100 \%$ Security provided; Number of gates $=$ Number of CCTV or \\
Number of Security Guards \\
\hline $50 \%$ Security provided; Number of gates = Number of CCTV or \\
Number of Security Guards \\
\hline $25 \%$ Security provided; Number of gates = Number of CCTV or \\
Number of Security Guards \\
\hline No CCTV or Security guards are provided \\
\hline
\end{tabular}

Source: Author, 2020

As for the safety in the stations, the number of CCTV or security guards is dependent on the location and layout of the stations. Hence, a definite number of units cannot be set to determine the number of CCTV or security guards. For this case, similar to the previous guidelines, the number of gates is benchmarked to decide on the units to be installed. Therefore, the number of CCTV or security guards is equivalent to the number of units needed for each station is considered $100 \%$ accommodated. The entire purpose of this benchmarking is to set the basic unit needed for the surveillances in the stations.

\section{Conclusions}

This study has reviewed literatures of BRT scoring system from ITDP and Federal Transit Administration and the scoring systems and counter-measure techniques with applicability in Malaysian context. These recommendations focus on 3 main areas including the Demand Profiling, Universal Access and Amenities. Furthermore, this paper reflected the existing limitations in the BRT scoring system, and specifically recommended a rating system for Malaysian practice, which mainly focuses on the BRT stations. The proposed recommendations can complement the BRT Scoring systems and create a more relevant scoring system for Malaysian context.

\section{Acknowledgments}

This study is funded by the Fundamental Research Grant Scheme (FRGS) from the University of Nottingham Malaysia. First author would also like to thank University of Nottingham Malaysia for providing full scholarship for this $\mathrm{PhD}$ study. Many thanks to the co-authors, colleagues who contributed advices and expertise which abundantly assisted the review journal. Also, would like to thank Nottingham University Malaysia for fully supporting the research, the immense support from the university and the authors made the process way more constructive.

\section{REFERENCES}

[1] A. Nikitas and M. Karlsson, "A worldwide state-of-the-art analysis for bus rapid transit: Looking for the success formula," J. Public Transp., vol. 18, no. 1, pp. 1-33, 2015, doi: 10.5038/2375-0901.18.1.3.

[2] Y. D. Wei, W. Xiao, M. Wen, and R. Wei, "Walkability, land use and physical activity," Sustain., vol. 8, no. 1, pp. 116, 2016, doi: 10.3390/su8010065.

[3] ITDP, “The BRT Standard,” p. 81, 2016.

[4] S. C. Wirasinghe, L. Kattan, M. M. Rahman, J. Hubbell, R. Thilakaratne, and S. Anowar, "Bus rapid transit - a review," Int. J. Urban Sci., vol. 17, no. 1, pp. 1-31, 2013, doi: 10.1080/12265934.2013.777514.

[5] S. A. R. Shah et al., "Performance evaluation of bus rapid transit system: A comparative analysis of alternative approaches for energy efficient eco-friendly public transport system," Energies, vol. 16, no. 3, 2020, doi: 10.3390/en13061377.

[6] J. Stutsman, "Bus Rapid Transit or Light Rail Transit," Transp. Res. Rec., vol. 1793, no. 1, pp. 55-61, 2002, doi: 10.3141/1793-08.

[7] A. M. Bento, M. L. Cropper, A. M. Mobarak, and K. Vinha, "The effects of Urban spatial structure on travel demand in the United States," Rev. Econ. Stat., vol. 87, no. 3, pp. 466478, 2005, doi: 10.1162/0034653054638292.

[8] B. Alam, H. Nixon, and Q. Zhang, "Investigating the Determining Factors for Transit Travel Demand by Bus Mode in US Metropolitan Statistical Areas," Mineta Transp. Inst., 2015.

[9] M. De Recherche, "A Distributed Simulation Environment for Cyber-Physical Systems," vol. 9255, no. September 2015, pp. 279-308, 1996, doi: 10.1016/S0195-9255(96)00023-6.

[10] M. Kuby, A. Barranda, and C. Upchurch, "Factors influencing light-rail station boardings in the United States," Transp. Res. Part A Policy Pract., vol. 38, no. 3, pp. 223247, 2004, doi: 10.1016/j.tra.2003.10.006.

[11] A. Chakraborty and S. Mishra, "Land use and transit ridership connections: Implications for state-level planning agencies," Land use policy, vol. 30, no. 1, pp. 458-469, 2013, doi: 10.1016/j.landusepol.2012.04.017.

[12] J. L. E. Andersen and A. Landex, "Catchment areas for public transport," WIT Trans. Built Environ., vol. 101, pp. 175-184, 2008, doi: 10.2495/UT080171.

[13] M. A. Berawi, G. Saroji, F. A. Iskandar, B. E. Ibrahim, P. Miraj, and M. Sari, "Optimizing Land Use Allocation of Transit-Oriented Development (TOD) to Generate Maximum Ridership," Sustainability, vol. 12, no. 9, p. 3798, 2020, doi: 10.3390/su12093798. 
[14] W. B. Group, "Universal Access in Urban Areas," no. December, 2017.

[15] W. Ramps, "Ramps and Curb Ramps," pp. 1-19.

[16] S. Stark, "Part impacts of amenities," pp. 20-48, 1996.

[17] H. Levinson et al., Transit Cooperative Research Program Report 90, vol. 1. 2003.
[18] I. Project for Public Spaces and I. Multisystems, "TCRP Report 46: The Role of Transit Amenities and Vehicle Characteristics in Building Transit Ridership - Amenities for Transit Handbook and the Transit Game Design," TCRP Rep. 46, 1999.

[19] APTA, "Crime Prevention Through Environmental Design ( CPTED ) for Transit Facilities," Transportation (Amst)., 2010. 